\title{
ENDOCARDITE BACTERIANA E O TRATAMENTO ENDODÔNTICO: ETIOLOGIA E PROCESSO TERAPÊUTICO
}

\author{
BACTERIAL ENDOCARDITIS AND ENDODONTIC TREATMENT: ETHOLOGY AND \\ THERAPEUTIC PROCESS
}

\section{ENDOCARDITIS BACTERIANA Y TRATAMIENTO ENDODÓNTICO: ETOLOGÍA Y PROCESO TERAPÉUTICO}

Filipe de Almeida Agra Omena ${ }^{1}$, André de Almeida Agra Omena², Jacyara Abeacy Azevedo de Andrade ${ }^{3}$, Janyara Anny Azevedo de Andrade ${ }^{4}$, Layane Sobreira Bento ${ }^{5}$, Matheus Harllen Gonçalves Veríssimo ${ }^{6}$

\section{RESUMO}

e321208

https://doi.org/10.47820/recima21.v3i2.1208

A endocardite infecciosa é a causa primária de infecções cardíacas, sendo uma doença definida por contaminação microbiana da superfície endotelial das câmaras cardíacas e válvulas cardíacas. Objetivo: realizar uma revisão integrativa da literatura sobre o tratamento endodôntico e sua relação com a endocardite bacteriana. Metodologia: foi realizada uma busca da literatura através das bases de dados eletrônica: UpDate; Science Direct; LILACS (Literatura Latino-Americana e do Caribe em Ciências da Saúde) e uma biblioteca eletrônica: SciELO. Foram utilizadas duas palavras-chave para a composição da base de pesquisa, sendo o DeCS: "Bacterial, Endocarditis"; e o termo-livre: "Endodontic treatment". Os artigos foram avaliados quanto aos critérios de inclusão e exclusão pré-estabelecidos. Resultados e Discussão: dos 13 artigos que se adequaram aos critérios, apenas 5 foram selecionados para compor o estudo, já que 8 artigos não abordavam o desenvolvimento da endocardite bacteriana decorrente de tratamento endodôntico e seus processos terapêutico. Alguns estudos comprovaram a presença de bactérias bucais em câmaras valvares do coração, mostrando a possível consequência de um tratamento endodôntico malsucedido. $O$ processo terapêutico da endocardite possui dois princípios, mas o mais preconizado é o cirúrgico, pela possibilidade de surgimento de hemorragia pelo tratamento anticoagulante, podendo ser necessária a prescrição antibiótica. Considerações Finais: o conjunto de fatores como a má higiene bucal, o insucesso de um tratamento endodôntico e algumas complicações sistêmicas podem desencadear uma endocardite infecciosa, entretanto, a literatura carece de ensaios clínicos randomizados triplo-cegos para que seja comprovada a influência direta do tratamento endodôntico com a endocardite.

PALAVRAS-CHAVE: Endocardite. Endocardite bacteriana. Endodontia.

\begin{abstract}
Infective endocarditis is a primary cause of infections, being a definition defined by microbial diseases of the endothelial surface of the cardiac and cardiac chambers. Objective: to carry out an integrative review of the literature on endodontic treatment and its relationship with bacterial endocarditis. Methodology: a literature search was carried out through electronic databases: UpDate; Direct Science; LILACS (Latin American and Caribbean Literature on Health Sciences) and an electronic library: SCIELO. There were two keywords for the composition used in the search key, the DeCS being: "Bacterial, Endocarditis"; and the free term: "Endodontic treatment". Articles were included according to pre-established inclusion and exclusion criteria. Results and Discussion: of the 13 articles that met the selected criteria, only 8 articles did not address the development of bacterial endocarditis resulting from endodontic treatment and its therapeutic processes. studies prove the presence of oral bacteria in some cardiac treatments, the possibility of an unsuccessful endodontic treatment. The therapeutic
\end{abstract}

\footnotetext{
1 Acadêmico de medicina do Centro Universitário UNIFACISA

2 Acadêmico de medicina do Centro Universitário UNIFACISA

${ }^{3}$ Acadêmica de medicina do Centro Universitário UNIFACISA

${ }^{4}$ Acadêmica de medicina do Centro Universitário UNIFACISA

${ }^{5}$ Acadêmica de medicina do Centro Universitário UNIFACISA

${ }^{6}$ Acadêmico de odontologia da Universidade Estadual da Paraíba (UEPB) - Araruna
} 


\section{RECIMA21 - REVISTA CIENTÍFICA MULTIDISCIPLINAR ISSN 2675-6218}

ENDOCARDITE BACTERIANA E O TRATAMENTO ENDODÔNTICO: ETIOLOGIA E PROCESSO TERAPÊUTICO Filipe de Almeida Agra Omena, André de Almeida Agra Omena, Jacyara Abeacy Azevedo de Andrade, Janyara Anny Azevedo de Andrade, Layane Sobreira Bento, Matheus Harllen Gonçalves Veríssimo

process of endocarditis has two principles, but the most pre-configured is the surgical one due to the possibility of hemorrhage due to anticoagulant treatment, and an antibiotic prescription may be necessary. Final Considerations: factors such as poor clinical hygiene in the endodontic treatment and some systemic complications may occur from oral trials, the literature randomized lo-c and direct influence of the treatment so that it is proven to be in oral trials, the literature randomized lo-c and direct influence of treatment that is proven to be randomized clinical trials. endodontic treatment with endocarditis.

KEYWORDS: Endocarditis. Bacterial endocarditis. Endodontics.

\section{RESUMEN}

La endocarditis infecciosa es una causa primaria de infecciones, siendo una definición definida por enfermedades microbianas de la superficie endotelial del corazón y cámaras cardíacas. Objetivo: realizar una revisión integradora de la literatura sobre el tratamiento endodóntico y su relación con la endocarditis bacteriana. Metodología: se realizó una búsqueda bibliográfica a través de bases de datos electrónicas: UpDate; ciencia directa; LILACS (Literatura Latinoamericana y del Caribe en Ciencias de la Salud) y una biblioteca electrónica: SciELO. Se utilizaron dos palabras clave para la composición en la clave de búsqueda, siendo el DeCS: "Bacterial, Endocarditis"; y el término libre: "Tratamiento de endodoncia". Los artículos fueron incluidos según criterios de inclusión y exclusión preestablecidos. Resultados y Discusión: de los 13 artículos que cumplieron con los criterios seleccionados, solo 8 artículos no abordaron el desarrollo de endocarditis bacteriana resultante del tratamiento endodóntico y sus procesos terapéuticos. Los estudios demuestran la presencia de bacterias orales en algunos tratamientos cardíacos, la posibilidad de un tratamiento de endodoncia sin éxito. El proceso terapéutico de la endocarditis tiene dos principios, pero el más preconfigurado es el quirúrgico debido a la posibilidad de hemorragia por tratamiento anticoagulante, pudiendo ser necesaria la prescripción de antibióticos. Consideraciones finales: factores como la mala higiene clínica en el tratamiento de endodoncia y algunas complicaciones sistémicas pueden ocurrir a partir de ensayos orales, la literatura aleatoriza lo-c e influencia directa del tratamiento para que se demuestre en ensayos orales, la literatura aleatoriza lo-c-c e influencia directa del tratamiento que se ha demostrado que son ensayos clínicos aleatorizados. tratamiento endodóntico con endocarditis.

PALABRAS CLAVE: Endocarditis. Endocarditis bacteriana. Endodoncia.

\section{INTRODUÇÃO}

A endocardite bacteriana é um processo patológico causado pela infecção das válvulas do coração ou das superfícies endoteliais do músculo cardíaco (SANTOS et al., 2020). A princípio, as bactérias utilizam as células de um trombo vascular como núcleo de proliferação, propiciando o desenvolvimento de um processo infeccioso em região cardíaca (CINTRA, 2015; REIS et al., 2016; BIRNARD, 2018; MONTANO et al., 2021).

O tratamento endodôntico é uma técnica comumente usada para prevenir, diagnosticar e tratar as doenças da polpa e do periápice, mantendo o dente na arcada dentária (OLIVEIRA et al., 2018; BOSSARDI et al., 2019). A sua finalidade é restaurar uma saúde biológica, clínica e radiologicamente controlável, restaurando a função natural do elemento dentário no sistema estomatognático (AREDES et al., 2019; BLOCHOWAIAK, 2019). No entanto, este tratamento, se não for realizado de forma correta, pode acarretar a proliferação de colônias de bactérias para regiões do sistema vascular (SOUZA et al., 2016; BIRNARD, 2018; LAFAURIE et al., 2019). 


\section{RECIMA21 - REVISTA CIENTÍFICA MULTIDISCIPLINAR ISSN 2675-6218}

ENDOCARDITE BACTERIANA E O TRATAMENTO ENDODÔNTICO: ETIOLOGIA E PROCESSO TERAPÊUTICO Filipe de Almeida Agra Omena, André de Almeida Agra Omena, Jacyara Abeacy Azevedo de Andrade, Janyara Anny Azevedo de Andrade, Layane Sobreira Bento, Matheus Harllen Gonçalves Veríssimo

Outrossim, as lesões endodônticas propiciam ao acúmulo de bactérias por conta da dilatação vascular nos tecidos do periápice, abrindo portas para a entrada desses microrganismos na corrente sanguínea (ARAÚJO-JÚNIOR et al., 2019). As áreas mais comuns alcançadas pela endocardite bacteriana são as válvulas cardíacas, principalmente aquelas localizadas do lado esquerdo do coração (válvula mitral e válvula aórtica), sobretudo se já apresentam lesão ou refluxo (CINTRA, 2015).

Dessa forma, este artigo científico tem como objetivo realizar uma revisão integrativa da literatura sobre o tratamento endodôntico e sua relação com a endocardite bacteriana, determinando quais os principais aspectos influenciadores no desenvolvimento da endocardite bacteriana decorrente de tratamento endodôntico e seus processos terapêuticos.

\section{MÉTODO}

Esta revisão integrativa da literatura possui uma metodologia qualitativa, sendo baseada em Rother (2007) e Pereira et al. (2018), e no desenvolvimento da seguinte pergunta norteadora de pesquisa: Quais os principais aspectos influenciadores no desenvolvimento da endocardite bacteriana decorrente de tratamento endodôntico e seus processos terapêuticos?

Para isto, foram utilizadas as seguintes bases de dados eletrônica: UpDate; Science Direct; LILACS (Literatura Latino-Americana e do Caribe em Ciências da Saúde) e uma biblioteca eletrônica: SCIELO, para pesquisar e identificar estudos que respondessem à pergunta norteadora desta revisão integrativa da literatura.

Esta revisão integrativa baseou-se em cinco etapas: Na primeira etapa foi o estabelecimento dos descritores para ambas as bases de dados, sendo uma com a utilização de descritores (DeCS). Em seguida, na segunda etapa, fora feito a busca avançada nas bases e análise do quantitativo dos artigos científicos presentes na íntegra. Logo em seguida, na terceira etapa, foram selecionados os artigos que se adequaram aos critérios de elegibilidade estabelecidos pelos pesquisadores. Na quarta e quinta etapa, os pesquisadores formularam uma tabela descritiva sobre os autores, objetivo da pesquisa, protocolo, resultados e conclusão e, em seguida, desenvolvimento da discussão dos artigos científicos para uma análise do tratamento endodôntico e sua relação com a endocardite bacteriana, a fim de responder à pergunta norteadora estabelecida no início desta metodologia.

Foram utilizadas duas palavras-chave para a composição da chave de pesquisa, sendo o DeCS: "Bacterial, Endocarditis"; e o termo-livre: "Endodontic treatment". Em seguida, os pesquisadores selecionaram os trabalhos com análise no título e resumo, com base nos critérios de elegibilidade. Os critérios de elegibilidade foram os seguintes: artigos que se adequem à temática; não houveram restrições quanto ao ano e idioma.

Também foi utilizado o sistema de formulário avançado para busca e seleção dos artigos utilizando conector booleano "AND". Em seguida, artigos que preencheram os critérios de elegibilidade foram identificados e incluídos na revisão. Os trabalhos que preencheram todos os critérios de seleção 


\section{RECIMA21 - REVISTA CIENTÍFICA MULTIDISCIPLINAR ISSN 2675-6218}

ENDOCARDITE BACTERIANA E O TRATAMENTO ENDODÔNTICO: ETIOLOGIA E PROCESSO TERAPÊUTICO Filipe de Almeida Agra Omena, André de Almeida Agra Omena, Jacyara Abeacy Azevedo de Andrade, Janyara Anny Azevedo de Andrade, Layane Sobreira Bento, Matheus Harllen Gonçalves Veríssimo

foram incluídos no estudo, os que não preencheram os critérios e/ou não se mostraram relevantes foram excluídos.

\section{RESULTADOS E DISCUSSÃO}

Com a busca avançada através da utilização dos descritores (DeCS) já mencionados junto com o conector booleano, foram selecionados apenas os artigos que entraram nos critérios de inclusão. Os resultados por análise foram representados na Tabela 1:

Tabela 1 - Seleção dos artigos por análise empregada e estabelecimento dos critérios de inclusão.

\begin{tabular}{ccccc}
\hline & Íntegra & Duplicados & $\begin{array}{c}\text { Adequados aos } \\
\text { critérios }\end{array}$ & Artigos selecionados \\
\hline Lilacs & 3 & 3 & 0 & 0 \\
Scielo & 1 & 0 & 1 & 1 \\
ScienceDirect & 160 & 4 & 9 & 3 \\
UpToDate & 150 & 0 & 4 & 1 \\
\hline Total & & & & 5
\end{tabular}

Fonte: Elaborado pelos autores, 2021.

Dos 13 artigos que se adequaram aos critérios, apenas 5 foram selecionados para compor o estudo, já que 8 artigos não abordavam o desenvolvimento da endocardite bacteriana decorrente de tratamento endodôntico e seus processos terapêutico. Para isso, estabeleceu-se a construção da Tabela 2 aos estudos clínicos selecionados, com formulação das colunas (Autor/Ano; Objetivo; Resultados; Conclusão).

Tabela 2 - Relatos de casos detalhados em tabela de resultados.

\begin{tabular}{|c|c|c|c|}
\hline Autor/Ano & Objetivo & Resultados & Conclusão \\
\hline Reis et al. 2016. & $\begin{array}{l}\text { Avaliou-se a incidência } \\
\text { de bacteremia após o } \\
\text { preparo do canal } \\
\text { radicular em dentes } \\
\text { com polpas necróticas } \\
\text { e periodontite apical. }\end{array}$ & $\begin{array}{l}\text { A cultura não revelou } \\
\text { bacteremia em todos } \\
\text { os indivíduos. A } \\
\text { análise por qPCR } \\
(P C R \text { em tempo real) } \\
\text { mostrou que o DNA } \\
\text { bacteriano ocorreu em } \\
\text { todas as amostras de } \\
\text { canal radicular. qPCR } \\
\text { mostrou uma } \\
\text { incidência semelhante } \\
\text { de bacteremia entre } \\
\text { os pacientes que } \\
\text { receberam ou não } \\
\text { terapia antibiótica } \\
\text { profilática (P> 0,05). } \\
\text { Em amostras de } \\
\text { sangue colhidas } 5\end{array}$ & $\begin{array}{l}\text { Nenhuma bacteremia detectável foi } \\
\text { evidente por cultura após o } \\
\text { tratamento de canais radiculares } \\
\text { infectados. A análise molecular } \\
\text { revelou DNA bacteriano e } \\
\text { Streptococos no sangue de alguns } \\
\text { pacientes, sem diferença } \\
\text { significativa entre os indivíduos que } \\
\text { receberam ou não profilaxia } \\
\text { antibiótica. }\end{array}$ \\
\hline
\end{tabular}




\section{RECIMA21 - REVISTA CIENTÍFICA MULTIDISCIPLINAR ISSN 2675-6218}

ENDOCARDITE BACTERIANA E O TRATAMENTO ENDODÔNTICO: ETIOLOGIA E PROCESSO TERAPÊUTICO Filipe de Almeida Agra Omena, André de Almeida Agra Omena, Jacyara Abeacy Azevedo de Andrade, Janyara Anny Azevedo de Andrade, Layane Sobreira Bento, Matheus Harllen Gonçalves Veríssimo
serade,

\begin{tabular}{|c|c|c|c|}
\hline & & $\begin{array}{l}\text { minutos após os } \\
\text { procedimentos } \\
\text { endodônticos, as } \\
\text { bactérias foram } \\
\text { detectadas em } 2 \text { de } 11 \\
\text { (18\%) indivíduos que } \\
\text { não faziam uso de } \\
\text { antibióticos e em } 4 \text { de } \\
21 \text { (19\%) pacientes } \\
\text { sob profilaxia. Após } 30 \\
\text { minutos, a incidência } \\
\text { de bacteremia } \\
\text { diminuiu para } 2 \text { de } 21 \\
\text { (10\%) em pacientes } \\
\text { que tomavam } \\
\text { antibióticos e era } \\
\text { indetectável em } \\
\text { pacientes sem risco } \\
\text { de endocardite. }\end{array}$ & \\
\hline Montano et al. 2021. & $\begin{array}{lr}\text { Os autores avaliaram } \\
\text { os perfis demográfico, } \\
\text { cardiológico, } \\
\text { microbiológico } \\
\text { odontológico } \\
\begin{array}{l}\text { pacientes } \\
\text { endocardite }\end{array} \\
\text { relacionada } \\
\text { bactérias orais. }\end{array}$ & 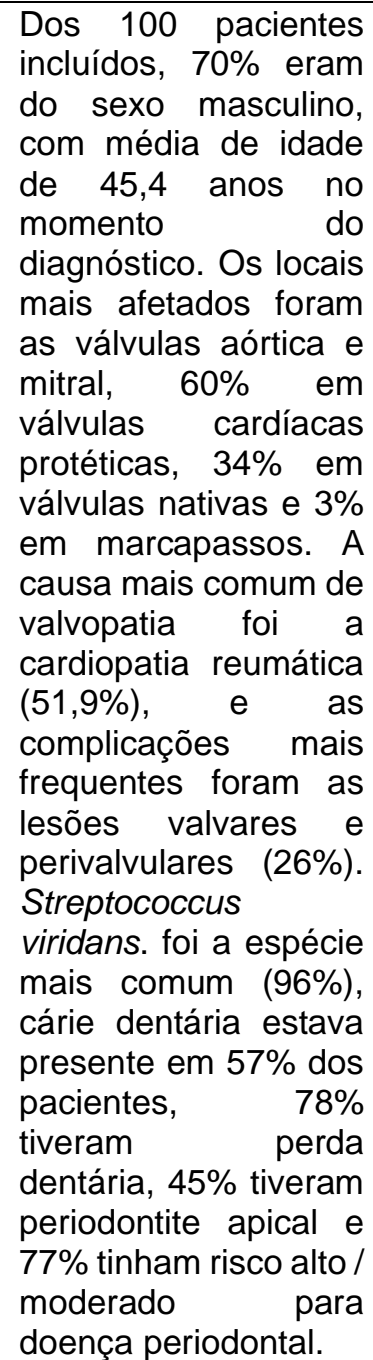 & $\begin{array}{l}\text { A endocardite relacionada com } \\
\text { bactérias orais entre os brasileiros } \\
\text { foi predominante nas próteses } \\
\text { valvares de homens jovens } \\
\text { previamente afetados por } \\
\text { cardiopatia reumática. } \\
\text { Streptococcus viridans foi a } \\
\text { principal causa de endocardite, } \\
\text { associada a pacientes com má } \\
\text { higiene bucal. }\end{array}$ \\
\hline Souza et al. 2016. & $\begin{array}{l}\text { Analisou-se se } 0 \\
\text { tratamento } \\
\text { odontológico antes da }\end{array}$ & $\begin{array}{l}\text { Do total da amostra, } \\
38 \text { pacientes }(8 \%) \\
\text { foram diagnosticados }\end{array}$ & $\begin{array}{l}\text { Os resultados não permitiram a } \\
\text { determinação do impacto do } \\
\text { tratamento odontológico antes do }\end{array}$ \\
\hline
\end{tabular}




\section{RECIMA21 - REVISTA CIENTÍFICA MULTIDISCIPLINAR ISSN 2675-6218}

ENDOCARDITE BACTERIANA E O TRATAMENTO ENDODÔNTICO: ETIOLOGIA E PROCESSO TERAPÊUTICO Filipe de Almeida Agra Omena, André de Almeida Agra Omena, Jacyara Abeacy Azevedo de Andrade, Janyara Anny Azevedo de Andrade, Layane Sobreira Bento, Matheus Harllen Gonçalves Veríssimo
une

cirurgia cardíaca valva (CVS) influenciou na ocorrência endocardite. com endocardite. Não foi detectada de diferença significativa $(\mathrm{p}=0,496)$ na comparação da ocorrência de endocardite no grupo com preparo dentário $(6,4 \%)$ e sem preparo dentário (8,4\%). O modelo de regressão logística confirmou que 0 tratamento odontológico não alterou 0 risco de endocardite $(\mathrm{p}=$ $0,504)$ e indicou que idade $(p<0,003)$ e sexo $(p=0,013)$ foram fatores de risco significativos. Houve alta demanda por procedimentos odontológicos no grupo que recebeu preparo dentário, não havendo diferenças significativas entre os pacientes com e sem endocardite.

$A$

hemocultura indicou diferenças qualitativas na comparação de pacientes com e sem tratamento odontológi-co, principalmente na frequência de Staphylococcus e Streptococcus.

Destrinchar
diagnóstico, cuidados,
manejo e tratamento
da endocardite
infecciosa em adultos.

Wang, 2022.

Pacientes com

endocardite por

organismos bucais

comuns devem ser

submetidos a uma avaliação

odontológica

completa. O exame

deve enfocar a

inflamação

periodontal, formação

de bolsas ao redor dos

dentes e cáries que

podem resultar em

infecção pulpar e

subsequente
CVS nos resultados de endocardite. No entanto, não foi possível excluir os potenciais efeitos benéficos de tal tratamento na prevenção da endocardite.

O diagnóstico precoce e tratamento
da endocardite são necessários
para reduzir o alto risco de
mortalidade associado a esta
doença.
da endocardite são necessários doença. 

ISSN 2675-6218

ENDOCARDITE BACTERIANA E O TRATAMENTO ENDODÔNTICO: ETIOLOGIA E PROCESSO TERAPÊUTICO Filipe de Almeida Agra Omena, André de Almeida Agra Omena, Jacyara Abeacy Azevedo de Andrade, Janyara Anny Azevedo de Andrade, Layane Sobreira Bento, Matheus Harllen Gonçalves Veríssimo
a

\begin{tabular}{|c|c|c|c|}
\hline & & $\begin{array}{l}\text { abscesso. Uma série } \\
\text { completa de } \\
\text { radiografias intraorais } \\
\text { permite a identificação } \\
\text { de cáries, doenças } \\
\text { periodontais e outras } \\
\text { doenças (ou seja, } \\
\text { fratura dentária) não } \\
\text { evidentes no exame } \\
\text { clínico. }\end{array}$ & \\
\hline Sexton et al., 2021. & $\begin{array}{lr}\text { Expor a } & \text { necessidade } \\
\text { ou não do uso } \\
\text { profilático } & \text { de } \\
\text { antibiótico } & \\
\text { pacientes cardiopatas } \\
\text { e não cardiopatas. }\end{array}$ & 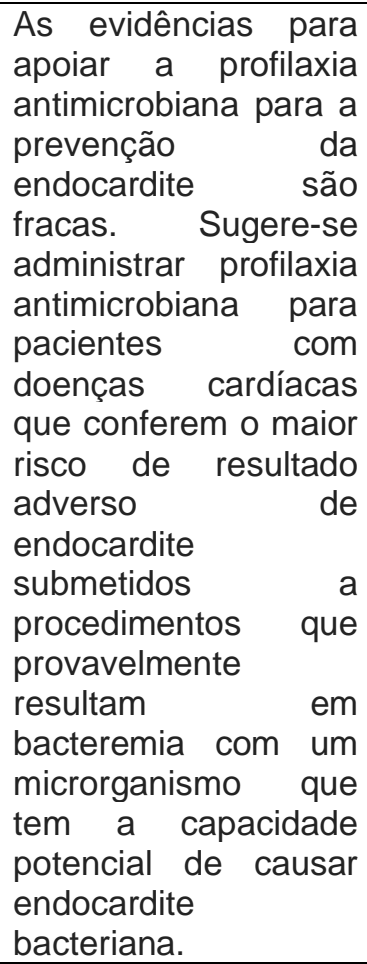 & $\begin{array}{l}\text { Entre os procedimentos de maior } \\
\text { risco para o desenvolvimento da } \\
\text { endocardite, incluem-se os } \\
\text { tratamentos odontológicos que } \\
\text { envolvem a manipulação do tecido } \\
\text { gengival ou da região periapical dos } \\
\text { dentes ou perfuração da mucosa } \\
\text { oral. Pacientes cardiopatas que irão } \\
\text { se submeter a procedimentos } \\
\text { odontológicos relevantes devem } \\
\text { receber terapia profilática com } \\
\text { amoxicilina oral } 2 \text { gramas. Além } \\
\text { disso, todos os indivíduos em risco } \\
\text { de desenvolver endocardite devem } \\
\text { estabelecer e manter um programa } \\
\text { de cuidados com a saúde bucal, } \\
\text { incluindo cuidados profissionais } \\
\text { regulares, o uso regular de escovas } \\
\text { de dente manuais ou elétricas, fio } \\
\text { dental e outros dispositivos para } \\
\text { remoção de placa bacteriana. }\end{array}$ \\
\hline
\end{tabular}

Fonte: Elaborado pelos autores, 2021.

A endocardite infecciosa é a causa primária de infecções cardíacas, sendo uma doença definida por contaminação microbiana, constituindo-se por bactérias ou fungos, da superfície endotelial das câmaras cardíacas e válvulas cardíacas (REIS et al., 2016). Sendo assim, é uma doença grave que atinge a superfície do endocárdio, ocorrendo de forma mais recorrente nas proximidades de cardiopatias congênitas ou adquiridas (SOUZA et al., 2016).

A higiene oral é um problema na precaução do progresso da endocardite infecciosa, pois poderia evitar o aumento no número de casos (SANTOS et al., 2020). A patogênese da endocardite tem sido relacionada ao quadro de bacteremia, cuja origem pode incluir locais de infecção periodontal, manipulação de tecidos dentários e/ou orais e até mesmo hábitos de vida diários (por exemplo, escovação e uso do fio dental) (SOUZA et al., 2016). As mais prováveis causas da endocardite bacteriana são as bacteremias transitórias espontâneas (ARAÚJO-JÚNIOR et al., 2019).

A bacteremia é a presença de bactérias na corrente sanguínea que pode ocorrer de forma espontânea, durante certas infecções teciduais, em consequência de procedimentos dentários e 


\section{RECIMA21 - REVISTA CIENTÍFICA MULTIDISCIPLINAR ISSN 2675-6218}

ENDOCARDITE BACTERIANA E O TRATAMENTO ENDODÔNTICO: ETIOLOGIA E PROCESSO TERAPÊUTICO Filipe de Almeida Agra Omena, André de Almeida Agra Omena, Jacyara Abeacy Azevedo de Andrade, Janyara Anny Azevedo de Andrade, Layane Sobreira Bento, Matheus Harllen Gonçalves Veríssimo

outros. A bacteremia pode causar infecções metastáticas, incluindo endocardite, especialmente nos pacientes com anormalidades valvares cardíacas, em que podemos observar os principais agentes etiológicos na Tabela 3 (LAFAURIE et al., 2019).

Tabela 3 - Agentes etiológicos mais frequentes

\begin{tabular}{lcccc}
\hline & $\begin{array}{c}\text { VÁLVULA } \\
\text { NATIVA }\end{array}$ & $\begin{array}{c}\text { Cirurgia } \\
<2 \text { meses }\end{array}$ & $\begin{array}{c}\text { Cirurgia } \\
2-12 \text { meses }\end{array}$ & $\begin{array}{c}\text { Cirurgia } \\
>12 \text { meses }\end{array}$ \\
\cline { 3 - 5 } $\begin{array}{l}\text { Streptococcus } \\
\text { sp. }\end{array}$ & $30-65 \%$ & $1 \%$ & $7-10 \%$ & $30-33 \%$ \\
\hline $\begin{array}{l}\text { Staphylococcus } \\
\text { aureus }\end{array}$ & $25-40 \%$ & $20-40 \%$ & $10-15 \%$ & $15-20 \%$ \\
\hline $\begin{array}{l}\text { Estafilococos } \\
\text { coagulase }(-)\end{array}$ & $3-8 \%$ & $30-35 \%$ & $30-35 \%$ & $10-12 \%$ \\
\hline Enterococos & $3-17 \%$ & $5-10 \%$ & $10-15 \%$ & $8-12 \%$ \\
\hline Bacilo Gram $(-)$ & $4-10 \%$ & $10-15 \%$ & $2-4 \%$ & $4-7 \%$ \\
\hline Fungos & $1-3 \%$ & $5-10 \%$ & $10-15 \%$ & $1 \%$ \\
\hline Outros & $1-2 \%$ & $6-7 \%$ & $2-6 \%$ & $2-8 \%$ \\
\hline
\end{tabular}

Fonte: Adaptado de Silva s.d.

A idade avançada, próteses valvares, insuficiência cardíaca, complicações peri-valvulares, acidente vascular cerebral e infecção por Staphylococcus aureus são os fatores adversos de prognósticos mais consideráveis da endocardite bacteriana (MONTANO et al., 2021).

Segundo Araújo-Júnior (2019), existem inúmeras causas e fatores de riscos relacionados à endocardite bacteriana, tendo incerteza na etiologia após os tratamentos dentários, em que as bacteremias transitórias espontâneas são as suas mais prováveis causas.

A contaminação de bactérias pode ocorrer de duas maneiras, por via hematogênica ou vias linfáticas. A disseminação hematogênica irá percorrer a nossa face a partir das veias que estão na região, como é o caso das veias angulares e oftálmicas, as quais não possuem válvulas permitindo um fluxo sanguíneo em qualquer direção, diferente dos vasos do coração que possuem valvas e permitem uma circulação unilateral (REIS et al., 2016).

Dessa forma, a drenagem venosa contaminada da face chegará à região do seio cavernoso através da disseminação hematogênica, levando assim a uma trombose do seio cavernoso e a chegada da infecção nos demais órgãos, como é o caso do coração que recebe sangue das veias. Ademais, as contaminações por vias linfáticas advêm da entrada do microrganismo no sistema linfático (LAFAURIE et al., 2019).

Diante disso, a infecção seguirá o percurso do fluido linfático pelos vasos linfáticos desembocando no sistema venoso, no qual a infecção pode se disseminar pelos demais órgãos e tecidos do nosso corpo (SOUZA et al., 2016). Outrossim, de acordo com Reis et al., (2016), a infecção periapical é a maneira mais comum de infecções, sendo causada pela invasão dos microrganismos 


\section{RECIMA21 - REVISTA CIENTÍFICA MULTIDISCIPLINAR ISSN 2675-6218}

ENDOCARDITE BACTERIANA E O TRATAMENTO ENDODÔNTICO: ETIOLOGIA E PROCESSO TERAPÊUTICO Filipe de Almeida Agra Omena, André de Almeida Agra Omena, Jacyara Abeacy Azevedo de Andrade, Janyara Anny Azevedo de Andrade, Layane Sobreira Bento, Matheus Harllen Gonçalves Veríssimo

nos canais radiculares e atingindo o forame apical, sendo ponto de acesso das bactérias nos tecidos periapicais.

A forma na qual ocorre a propagação das bactérias vai depender da fixação muscular até o ponto em que a infecção perfura. Caso a disseminação esteja fora das inserções musculares, a propagação irá para os espaços faciais e distais e, consequentemente, a infecções mais graves, exemplos: sinusite, obstrução das vias aéreas, trombose do seio cavernoso, abscesso cerebral ou até mesmo a morte (ORRETT; OGLE, 2017).

A principal bactéria relacionada ao mau estado de saúde bucal e a endocardite infecciosa é a Streptococcus viridans (LAFAURIE et al., 2019). Assim, quando se dissemina e atinge o coração, irá formar uma massa amorfa de fibrina e plaquetas nas estruturas do coração, com colônias de microrganismos e células inflamatórias, sendo a vegetação, isso é, lesão característica de endocardite (REIS et al., 2016).

Em pacientes imunocomprometidos, a bacteremia pode ter efeitos à distância e progredir para uma infecção sanguínea mais grave (septicemia) que apresenta sintomas como: náusea intensa, febre alta, taquicardia, calafrios e outros (ORRETT; OGLE, 2017). O processo terapêutico para a endocardite bacteriana pode ser por dois métodos: anticoagulante ou cirúrgico.

O tratamento anticoagulante não previne embolização na endocardite infecciosa e ainda pode aumentar o risco de hemorragia intracerebral, não sendo, portanto, usados rotineiramente no tratamento de endocardite. Nos pacientes com prótese valvar que usam anticoagulante, a anticoagulação pode ser mantida, porém é necessário acompanhamento cuidadoso. Deve-se suspender a anticoagulação, pelo menos temporariamente, se houver sinais de comprometimento do sistema nervoso central.

Além desse, o tratamento cirúrgico pode ser utilizado e reduz a mortalidade de pacientes com endocardite infecciosa que evoluem com insuficiência cardíaca refratária, acometimento perivalvar com abscessos ou doença não controlada, apesar de terapêutica antibiótica adequada em doses elevadas. Os pacientes com esse perfil devem ser encaminhados para avaliação em serviço de cirurgia cardiovascular. Pacientes com endocardite envolvendo próteses também necessitam de avaliação cirúrgica. O processo terapêutico para endocardite infecciosa pode variar de acordo com o agente etiológico, sendo representado na Tabela 4. 


\section{RECIMA21 - REVISTA CIENTÍFICA MULTIDISCIPLINAR ISSN 2675-6218}

ENDOCARDITE BACTERIANA E O TRATAMENTO ENDODÔNTICO: ETIOLOGIA E PROCESSO TERAPÊUTICO Filipe de Almeida Agra Omena, André de Almeida Agra Omena, Jacyara Abeacy Azevedo de Andrade, Janyara Anny Azevedo de Andrade, Layane Sobreira Bento, Matheus Harllen Gonçalves Veríssimo

Tabela 4 - Processo terapêutico de acordo com o agente etiológico.

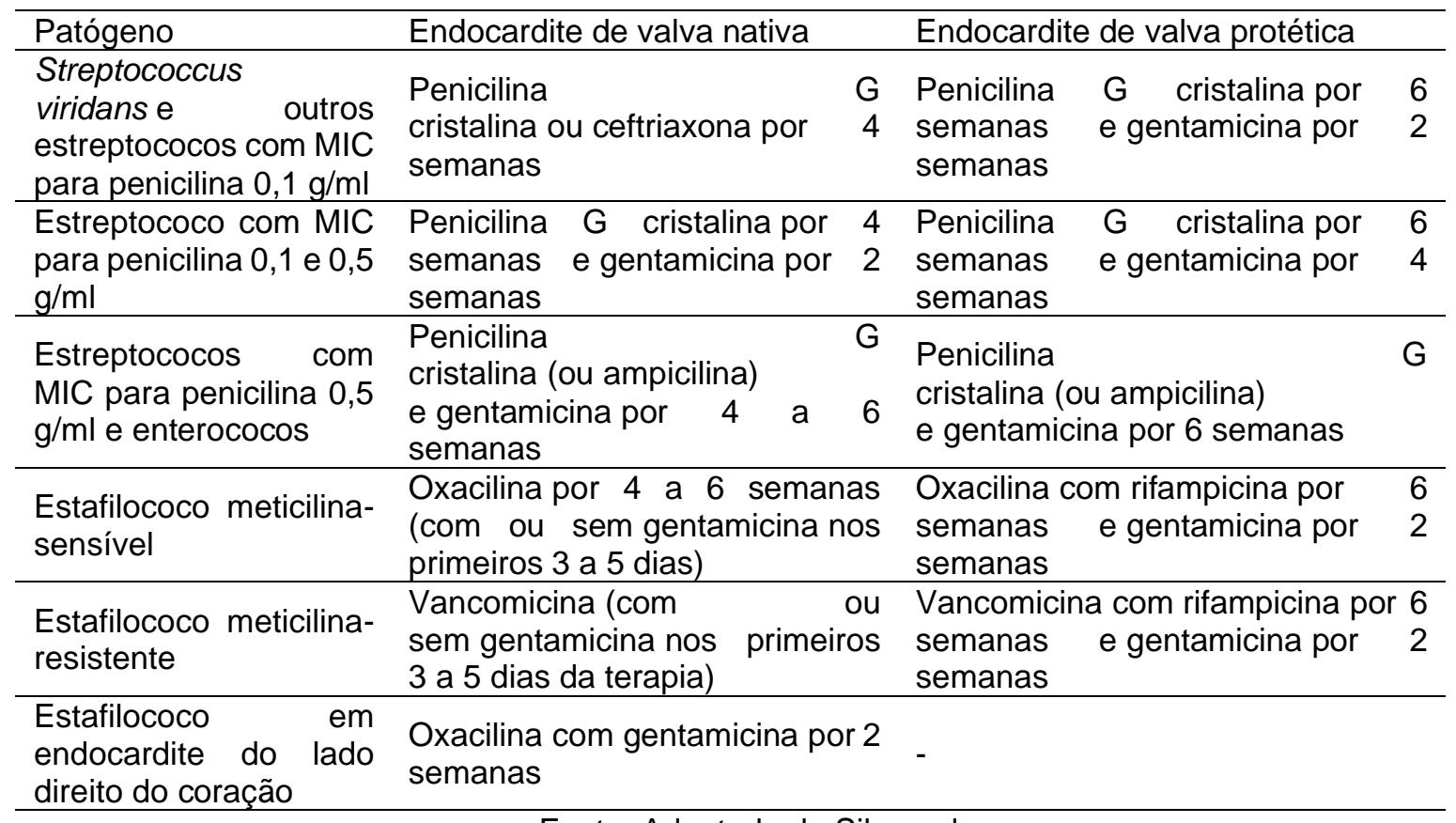

Fonte: Adaptado de Silva s.d.

Em estudo dirigido por Souza et al. (2016), dos 481 pacientes da amostra, 8\% foram identificados com endocardite, foram notadas alterações significativas na seguinte variável: sexo, pois a endocardite infecciosa foi mais frequente nos homens $(11,0 \%)$ do que nas mulheres $(5,5 \%)$. Já na pesquisa de Delahaye et al. (2016), foram apresentados em 238 pacientes (74\%) os portais de entrada para os atuais episódios de endocardite infecciosa. Dentre os identificados, $40 \%$ foram cutâneos, $29 \%$ orais ou dentários e $23 \%$ gastrointestinais.

No estudo de Reis et al. (2016), é comparada a presença de bacteremia em grupos de pacientes submetidos ao preparo do canal radicular em dentes com polpas necróticas e periodontite apical. No primeiro grupo de pacientes houve a administração da profilaxia antibiótica, diferentemente do segundo. Logo após o procedimento, amostras sanguíneas de cada grupo foram colhidas e submetidas a reação em qPCR a fim de determinar os níveis bacterianos e estreptocócicos totais. Por conseguinte, a incidência de bacteremia por Streptococos foi equivalente à de bactérias totais. Por fim, não houve diferença significativa entre indivíduos que receberam ou não a antibioticoprofilaxia.

Montano et al. (2021) analisaram o perfil demográfico de pacientes com endocardite infecciosa relacionada com bactérias orais, onde puderam perceber que a população mais afetada eram pessoas idosas, principalmente em países desenvolvidos. Foram analisados 2.255 dentes, onde os exames radiográficos apresentaram que $57 \%$ das amostras apresentavam cárie dentinária e os focos infecciosos orais foram confirmados radiograficamente em $74 \%$ dos pacientes, além das complicações como insuficiência cardíaca, embolia séptica sistêmica, complicações perivalvulares dentre outros. Dessa forma, a indicação de procedimentos cirúrgicos além do tratamento clínico/médico foi sugerida 


\section{RECIMA21 - REVISTA CIENTÍFICA MULTIDISCIPLINAR ISSN 2675-6218}

ENDOCARDITE BACTERIANA E O TRATAMENTO ENDODÔNTICO: ETIOLOGIA E PROCESSO TERAPÊUTICO Filipe de Almeida Agra Omena, André de Almeida Agra Omena, Jacyara Abeacy Azevedo de Andrade, Janyara Anny Azevedo de Andrade, Layane Sobreira Bento, Matheus Harllen Gonçalves Veríssimo

para $56 \%$ da amostra. Portanto, a principal causa da endocardite foi a Streptococcus Viridans, que estava relacionada com pacientes que estavam com um mal estado de saúde bucal.

No que concerne os estudos de Souza et al. (2016), observou-se que o tratamento odontológico antes da cirurgia cardíaca valvar (CVS) influenciou na ocorrência da endocardite, e do total da amostra, 38 pacientes foram diagnosticados com a endocardite, portanto, não havendo detecção na diferença significativa comparada da ocorrência de endocardite no grupo com preparo dentário $(6,4 \%)$ e sem preparo dentário $(8,4 \%)$. O tratamento odontológico não alterou o risco de endocardite - segundo o modelo de regressão logística - indicando que idade e sexo foram fatores de risco significativos, ocorrendo alta demanda por procedimentos odontológicos no grupo que recebeu o preparo dentário, e sem diferenças significativas entre os pacientes com ou sem endocardite. Apesar da hemocultura indicar diferenças qualitativas na comparação de pacientes com e sem tratamento odontológico com frequência, sobretudo de Staphylococcus e Streptococcus, os resultados não permitiram a determinação do impacto do tratamento odontológico antes do CVS nos resultados de endocardite, permitindo desse modo a não exclusão dos potenciais efeitos benéficos de tal tratamento na prevenção da patologia.

No estudo realizado por Sexton et al. (2021), teve como objetivo analisar a base teórica e a abordagem clínica para uso de profilaxia antimicrobiana para prevenção de endocardite bacteriana, foram realizados estudos em animais e humanos, cujo o primeiro apresenta que a terapia antimicrobiana tem a capacidade de prevenir a endocardite realizando a análise das bactérias de forma que o foco de infecção em uma válvula cardíaca suscetível não seja possível ou após as bactérias se focaram em uma área localizada de endotélio valvar danificado. Já os estudos humanos, vários foram realizados, tal como um resumo das limitações da profilaxia, o impacto dos procedimentos no risco de endocardite, o efeito da profilaxia antibiótica, bacteremia, o risco em si da endocardite e estudos de tendência temporal.

Com as evidências encontradas, recomenda-se o procedimento em relação a profilaxia de endocardite seguindo as diretrizes do American College of Cardiology/AHA. Por fim, evidências que sustentam a utilização da profilaxia antimicrobiana para a prevenção da endocardite são escassas, pois é mais provável que uma endocardite seja resultado da exposição a bacteremias associadas a atividades diárias, do que de bacteremia causada por um procedimento dentário, gastrointestinal ou geniturinário. Porém ainda é sugerido a aplicação de profilaxia antimicrobiana para pacientes com condições cardíacas com maior risco de efeito adverso de endocardite submetidos a procedimentos que resultam em bacteremia com um microrganismo que possa causar endocardite bacteriana.

No que tange ao escrito de Wang et al. (2021), para amenizar a taxa de morbidade, como também a mortalidade relacionada à endocardite infecciosa, é fundamental ter o diagnóstico e tratamento precoce por uma equipe multiprofissional. Ainda assim, os pacientes com endocardite valvar nativa do lado esquerdo, muitas vezes, precisam de cirurgia valvar precoce por motivo de ter uma ou mais complicações e, portanto, só deverá ser adiada para pacientes com complicações 


\section{RECIMA21 - REVISTA CIENTÍFICA MULTIDISCIPLINAR ISSN 2675-6218}

ENDOCARDITE BACTERIANA E O TRATAMENTO ENDODÔNTICO: ETIOLOGIA E PROCESSO TERAPÊUTICO Filipe de Almeida Agra Omena, André de Almeida Agra Omena, Jacyara Abeacy Azevedo de Andrade, Janyara Anny Azevedo de Andrade, Layane Sobreira Bento, Matheus Harllen Gonçalves Veríssimo

cerebrovasculares significativos ou aqueles com elevado parecer ou mau parecer a longo prazo por efeito de demais situações médicas.

\section{CONSIDERAÇÕES FINAIS}

Com a análise dos artigos científicos, o conjunto de fatores como a má higiene bucal, o insucesso de um tratamento endodôntico e algumas complicações sistêmicas podem desencadear uma endocardite infecciosa, entretanto, a literatura carece de ensaios clínicos randomizados triplocegos para que seja comprovada a influência direta do tratamento endodôntico com a endocardite.

Todavia, alguns estudos comprovaram a presença de bactérias bucais em câmaras valvares do coração, mostrando a possível ligação e consequência de um tratamento endodôntico mal sucedido e a ocorrência de endocardite bacteriana. O processo terapêutico da endocardite possui dois princípios, mas o mais preconizado é o cirúrgico pela possibilidade de surgimento de hemorragia pelo tratamento anticoagulante. Além disso, dependendo do agente etiológico, é necessária a prescrição medicamento de antibióticos como a penicilina e vancomicina.

Outrossim, pode-se observar a necessidade de novas pesquisas clínico-laboratoriais, com estudo de coorte e randomizados para melhor anuência dos resultados. Dessa forma, o artigo científico respondeu à pergunta norteadora e estabeleceu resultados satisfatórios para o objetivo préestabelecido.

\section{REFERÊNCIAS}

ARAÚJO-JÚNIOR, J. L. et al. Associação entre endocardite bacteriana e procedimento de cirurgia e traumatologia bucomaxilofacial. Arch Health Invest., v. 8, n. 3, p. 139-144, 2019.

AREDES, L. H. et al. Endocardite Infecciosa por Staphylococcus aureus devido à utilização de cateteres venosos central. Brazilian Journal of Surgery and Clinical Research, v. 28, n. 3, p. 80-86, 2019.

BIRNARD, L. Tratamento endodôntico como gatilho para endocardite infecciosa. 2018. Dissertação (Mestrado) - Universidade Fernando Pessoa, Porto, 2018. Disponível em: https://bdigital.ufp.pt/bitstream/10284/7192/1/PPG 29947.pdf. Acesso em: 04/02/2022.

BLOCHOWAIAK, J. K. Tratamento dentário e gestão recomendada em pacientes com risco de endocardite infecciosa. Kardiochirugia i Torakochirurgia Polska. p. 37-41, 2019.

BOSSARD, K. N. Manejo de pacientes com risco de desenvolver endocardite bacteriana: um desafio para cirurgiões-dentistas. 2019. TCC (Bacharel em Odontologia) - Centro Universitário FACVEST, Lages, SC, 2019.2 Disponível https://www.unifacvest.edu.br/assets/uploads/files/arquivos/33011-bossardi,-k-n.-manejo-depacientes-com-risco-de-desenvolver-endocardite-bacteriana--um-desafio-para-cirurgio\%CC\%83esdentistas.-unifacvest--lages,-tcc-defendido-em-19-dezembro-de-2019..pdf. Acesso em: 04 maio 2022.

CINTRA, J. L. Risco de endocardite bacteriana no tratamento endodôntico. Revista Investigação, v. 14, n. 1, p. 169-174, 2015. 


\section{RECIMA21 - REVISTA CIENTÍFICA MULTIDISCIPLINAR ISSN 2675-6218}

ENDOCARDITE BACTERIANA E O TRATAMENTO ENDODÔNTICO: ETIOLOGIA E PROCESSO TERAPÊUTICO Filipe de Almeida Agra Omena, André de Almeida Agra Omena, Jacyara Abeacy Azevedo de Andrade, Janyara Anny Azevedo de Andrade, Layane Sobreira Bento, Matheus Harllen Gonçalves Veríssimo

DELAHAYE, F. et al. Busca sistemática de portais de entrada atuais e potenciais para endocardite infecciosa. Jornal do Colégio Americano de Cardiologia, v. 67, n. 2, p.151-158, 2016.

LAFAURIE, G. I. et al. Impact of antibiotic prophylaxis on the incidence, nature, magnitude, and duration of bacteremia associated with dental procedures: a systematic review. The Journal of the American Dental Association, v. 150, n. 11, p. 948-959, 2019.

MONTANO, T. C. P. et al. Demographic, cardiological, microbiologic, and dental profiles of Brazilian patients who developed oral bacteria-related endocarditis. Oral Surgery, Oral Medicine, Oral

Pathology and Oral Radiology, v. 132, n. 4, p. 418-425, 2021.

OLIVEIRA, E. A. C. et al. Tratamento endodôntico em paciente cardiopata: revisão de literatura. Revista de Odontologia Contemporânea, v. 2, n. 2, p. 51-57, 2018.

ORRETT, E.; OGLE, D. Infecções odontogênicas. Clínicas odontológicas da América do Norte, v. 61, n. 2, p. 235-252, 2017.

PEREIRA, A. S. et al. Metodologia da pesquisa científica. Santa Maria, RS: Ed. UAB/NTE/UFSM. 2018. E-book.

REIS, L. C. et al. Bacteremia after endodontic procedures in patients with heart disease: culture and molecular analyses. Journal of Endodontics, v. 42, n. 8, p. 1181-1185, 2016.

ROTHER, E. T. Revisão sistemática X revisão narrativa. Acta paulista de Enfermagem, v. 20, n. 2, 2007.

SANTOS, J. M. et al. Desafios da endocardite infecciosa: uma revisão integrativa. Braz. J. Surg. Clin. Res., v. 32, n. 3, p. 75-83, 2020.

SEXTON, D. J. et al. Profilaxia antimicrobiana para a prevenção da endocardite bacteriana. UptoDate, oct. 2021. Disponível em: https://www.uptodate.com/contents/antimicrobial-prophylaxis-for-theprevention-of-bacterial-

endocarditis?search=Bacterial,\%20Endocardits\%20AND\%20endodontic\%20treatment\&source=searc

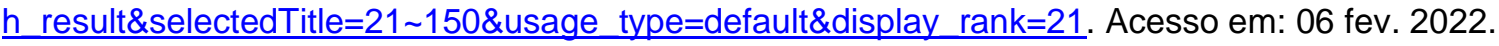

SILVA, V. M. Endocardite infecciosa. $[S . \quad$ l.: s. $\quad$ n.], $\quad$ s.d. Disponível em: http://www.fmt.am.gov.br/manual/endocardite.htm\#: :text=Na\%20endocardite\%20infecciosa\%20suba guda\%20pode,da\%20cultura\%20e\%20do\%20antibiograma. Acesso em: 07 fev. 2022.

SOUZA, A. F. et al. Dental care before cardiac valve surgery: is it importante to prevent infective endocarditis?. I. J. C. Heart \& Vasculature, v. 12, p. 57-62, 2016.

WANG, A. et al. Visão geral do manejo da endocardite infecciosa em adultos. UptoDate, jan. 2022. Disponível em: https://www.uptodate.com/contents/overview-of-management-of-infectiveendocarditisinadults? search=Bacterial,\%20Endocardits\%20AND\%20endodontic\%20treatment\&sourc e=search result\&selectedTitle=1 150\&usage type=default\&display rank=1\#H3652469325. Acesso em: 06 fev. 2022. 